
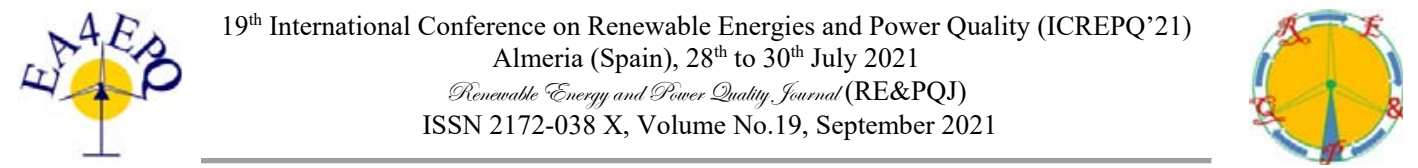

\title{
Power Quality Improvements in Grid-Connected PV System Using Hybrid Technology
}

\author{
Prasad Kumar Bandahalli Mallappa, Herminio Martínez-García and Guillermo Velasco-Quesada \\ Department of Electronic Engineering \\ Escola d'Enginyeria de Barcelona Est (EEBE), Technical University of Catalonia (UPC)-BarcelonaTech \\ Campus of Diagonal-Besòs, 08019 Barcelona (Spain)
}

Phone/Fax number:+0034.93.413.72.90, e-mail: prasad.kumar.bandahalli@upc.edu, herminio.martinez@upc.edu

\begin{abstract}
In recent trends, photo-voltaic (PV) is mostly build upon competitive technological development of power quality (PQ) issues. In this article, a hybrid control strategy is implemented with multi-level inverter (MLI) to improve PQ features. As a result, the combination of these controllers with suitable level of MLI could improve the PQ features in a significant way.
\end{abstract}

Key words. Multi-level inverter (MLI), Photo-voltaic (PV) energy, Power quality (PQ), Hybrid control, Electrical microgrids (MGs).

\section{Introduction}

Nowadays, Technologies in RES have got more opportunities for promoting PV for generating electric power. At present, the counting of renewable source of energy and its sizes are extending to growing rapidly, correspondingly with the influence of power system [1]. The electrical grids are steadily developing because of its stable technical confrontation it would have to meet; the involvement of distributive generation, renewable source of energy, power flow with bidirectional, etc.

In this powerful setting, it is a requirement that this system can able to sustain increasing the count of users although assurance to few conditions. By connecting more number of renewable sources into the grid required to be addressed carefully to suppress few power quality parameters [2]. Nowadays, by connecting RES with the power grid have reached notable penetration and it can affect the quality of power and stability of grid. By using phase locked loop (PLL) algorithm, control some of the parameters and reduced the inaccuracy to provide better operation [3].

In recent trends, there is a massive development in both domestic and industrial appliances. Power systems with the badness that leads to damage produce their components owing to process of overheating. In these power systems, there are, in addition, some common problems such as harmonic distortion, voltage sag, transient, spikes etc. [4]. Multi-Level Inverter gives the output value as high from the voltage of medium source. This technique is performed to produce the system with improved power quality and, in addition, reduces the stress voltage on the load. One of the most important devices used for eliminating the distortion is filter [5]. By the use of filter, compensating the disturbance of harmonics and enhance the system improvement. When the system is connected with load, efficiency of filter is based on harmonic disturbance of both the current and voltage. Filters included in the system provide controlling the reactive power, correction of power factor and filtering the harmonics [6].

\section{Literature Review and Objective}

In this section, a discussion of various existing techniques that are developed for effective power supply in grid connected PV-array, including improvement of the power quality, are presented. In particular, some of then are shown in Table I.

Nowadays, MLI with novel control strategy provides the better results for reduction of THD and switching loss. For calculating the switching angle, a hybrid control strategy is the excellent choice for predicting the angle. And, in addition, it can provide the specific fundamental voltage by eliminating the harmonics.

- Reduction of THD in current waveforms will increase the performance of the system and also make the output voltage as stable one.

- Provide specific switching frequency through proper control strategy to reduce the harmonic distortion and switching loss.

- By using novel technique to reduce the current THD, inverter cost and filter size gets reduced to improve the efficiency.

- By minimizing the switching loss provide the result with accuracy and make robust with lower dynamic response. 
Table I: Characteristics of the inverter.

\begin{tabular}{|c|c|c|c|c|}
\hline Authors & Methodology & Advantages & Limitations & $\begin{array}{l}\text { Performance } \\
\text { Metrics }\end{array}$ \\
\hline $\begin{array}{c}\text { I. Ali, et al., } \\
\text { [7] }\end{array}$ & $\begin{array}{l}\text { Introduced a modified } \\
\text { efficient variable step Perturb } \\
\text { and Observe (VSPO) } \\
\text { algorithm to solve the } \\
\text { Maximum Power Point } \\
\text { (MPP) under a rapidly } \\
\text { changing insolation problem. }\end{array}$ & $\begin{array}{l}\text { The proposed algorithm } \\
\text { improves the system } \\
\text { response and reduces the } \\
\text { steady state voltage } \\
\text { oscillations, which improve } \\
\text { the system efficiency. }\end{array}$ & $\begin{array}{l}\text { The output power of the } \\
\text { proposed algorithm tracks } \\
\text { the irradiance profile, } \\
\text { however, the output power } \\
\text { is decreased due to the } \\
\text { temperature rise. }\end{array}$ & $\begin{array}{l}\text { Active \& reactive } \\
\text { power, current, grid } \\
\text { current voltage, } \\
\text { reference \& actual } \\
\text { voltages and tracking } \\
\text { efficiency. }\end{array}$ \\
\hline $\begin{array}{c}\text { H. A. Mosalam, et } \\
\text { al., [8] }\end{array}$ & $\begin{array}{l}\text { Implemented a fuzzy logic } \\
\text { methodology to control a } \\
\text { grid- connected PV system } \\
\text { through Z-source inverter } \\
\text { using maximum constant } \\
\text { boost control method. }\end{array}$ & $\begin{array}{l}\text { The system response using } \\
\text { FLC is more suitable than } \\
\text { the traditional PI controller in } \\
\text { terms of less overshoot and } \\
\text { less settling time. } \\
\text { Also, the system is more } \\
\text { stable speedily and softly at } \\
\text { the desired value with } \\
\text { less oscillation. }\end{array}$ & $\begin{array}{l}\text { The proposed method did } \\
\text { not achieved better } \\
\text { performance than the PI } \\
\text { control system only, when } \\
\text { the MPPT block changes } \\
\text { the reference maximum } \\
\text { power. }\end{array}$ & $\begin{array}{l}\text { Active power, power } \\
\text { factor, grid currents } \\
\text { and PV output power } \\
\text { are used for the } \\
\text { validation. }\end{array}$ \\
\hline $\begin{array}{c}\text { M. Lakshmi, and S. } \\
\text { Hemamalini, [9] }\end{array}$ & $\begin{array}{l}\text { Designed a decoupled } \\
\text { control of grid connected PV } \\
\text { system using Fractional } \\
\text { Order Proportional- Integral } \\
\text { (FOPI) controller. }\end{array}$ & $\begin{array}{l}\text { This feature of FOPI } \\
\text { controller improves the } \\
\text { system efficiency by } \\
\text { reducing the losses caused } \\
\text { by THD during the variable } \\
\text { irradiation and load } \\
\text { condition. The significant } \\
\text { reduction in the grid current } \\
\text { THD is achieved by } \\
\text { injecting less oscillation } \\
\text { current to the grid. }\end{array}$ & $\begin{array}{l}\text { The inductance of a LCL } \\
\text { filter is small as compared } \\
\text { to the L filter to minimize } \\
\text { the harmonics at the } \\
\text { switching frequency. } \\
\text { The increase in amplitude } \\
\text { at resonant frequency } \\
\text { causes instability of the } \\
\text { overall system. }\end{array}$ & $\begin{array}{l}\text { DC link regulation, } \\
\text { system response and } \\
\text { output current. }\end{array}$ \\
\hline $\begin{array}{l}\text { M. Aourir, et al., } \\
{[10]}\end{array}$ & $\begin{array}{c}\text { Presents the control } \\
\text { development of a single } \\
\text { stage grid- connected PV } \\
\text { system using a nonlinear } \\
\text { cascade controller based on } \\
\text { average state space model. } \\
\text { [A single-phase half- } \\
\text { bridge inverter] } \\
\end{array}$ & $\begin{array}{l}\text { A multi-loop controller is } \\
\text { designed by using back- } \\
\text { stepping and Lyapunov } \\
\text { approaches for the power } \\
\text { factor correction objective } \\
\text { ensure the power balance } \\
\text { between the } \\
\text { grid and PV panels. } \\
\end{array}$ & $\begin{array}{l}\text { However, the residual } \\
\text { ripples of low amplitude } \\
\text { affects all signals in the } \\
\text { control system. }\end{array}$ & $\begin{array}{l}\text { DC bus voltage, grid } \\
\text { current, PV panels } \\
\text { power, grid power, } \\
\text { harmonic content and } \\
\text { power factor. }\end{array}$ \\
\hline
\end{tabular}

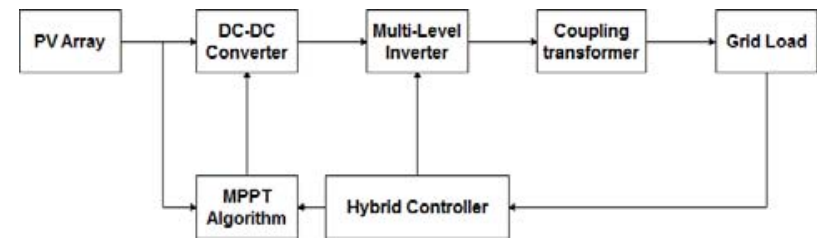

Fig. 1. General block diagram of proposed method.

\section{Proposed Method}

The PV array generates electric power with the help of PV radiations and the output from the $\mathrm{PV}$ is DC. The highest power from the PV can be extracted from the maximum power point. However, the effectiveness of the PV is depending upon the irradiance and cell temperature, which deviates the power from the maximum power. Therefore, a control technique is required to track the MPP according to this change. The low irradiance can also cause PQ problems in the distribution grid.
The general block diagram of a grid-tied PV system is as shown in Fig. 1. Due to the energy demand of the electric utilities, PV is utilized in the grid-connected system to provide the essential power to the end users. However, the high penetration level of the PV in the distribution system affects the system performance in terms of power quality, stability and voltage regulation.

In the configuration process, both power conversion stages (DC-DC and DC-AC) are convoluted between PV and grid. The grid tied PV structure comprises of a PV panel, DC-DC converter, MLI and the grid. Nowadays, the boost converters are used widely in the industries due to the requirement of variable DC supply. The intermediate DC-DC converter fitted between the PV array and the inverter acts as an interface between the output DC voltage of the PV modules and the DC link voltage at the input of the voltage source inverter.

The voltage of the PV array is variable with unpredictable atmospheric factors, while the bus voltage is controlled to be kept constant at all load conditions. But the effectiveness of the PV array is depending upon the 
irradiance and cell temperature, which deviates the power from the maximum power. The feedback from the grid (Voltage, Current, THD, Active/Reactive power) is given to the controller which is already contains the input PV power also.

Figure 2 illustrates the control circuit diagram for the proposed method. When utilizing every duty cycle, it is necessary to pause the transient condition to resolve; the higher resultant number of particles will increase the tracking time of the MPP.

Another significant factor is a convergence of particle since the duty cycle does not receive some value which is not within the interval $[0,1]$. The particles should converge in this particular duration; else, the arrangement cannot discover the MPP. To confirm the particle values, the speed parameter has to be controlled which should not exceed the interval.

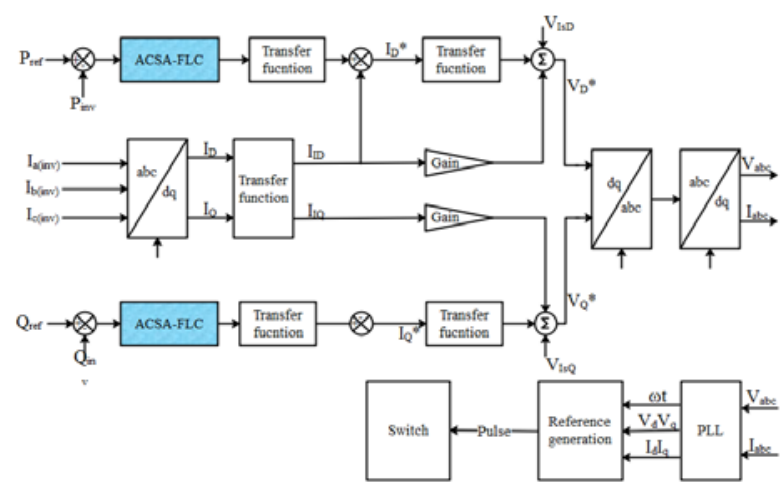

Fig. 2. Control circuit diagram.

\section{Simulation Results and Discussion}

This section presents the simulation outcomes that is associated to the PV system which is operating with ACSA-FLC. The simulation diagram for the grid connected PV system is shown in Fig. 3. Various assessments have been recognized afore relating the PV structure which is associating with some obtained results by means of traditional techniques.

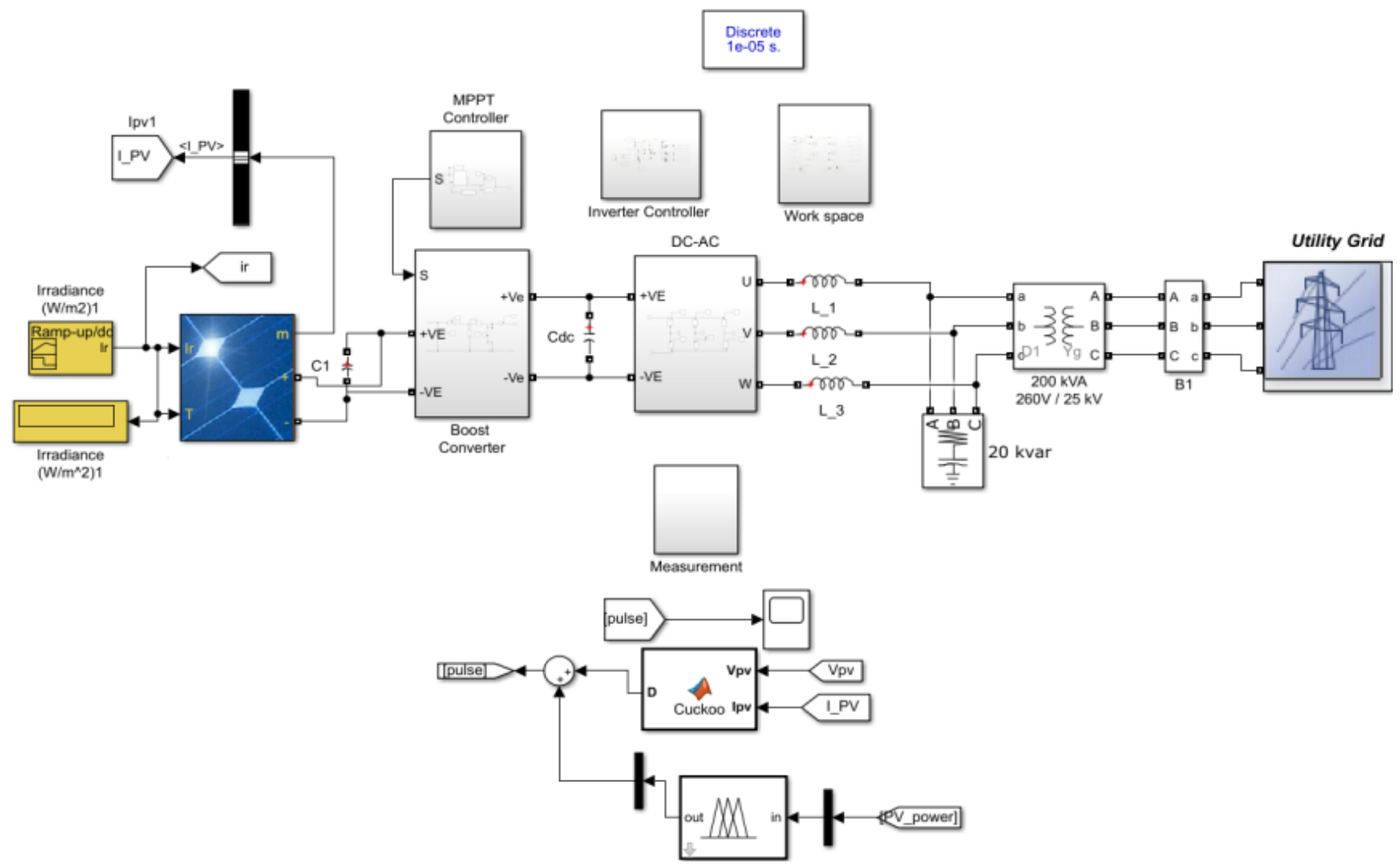

Fig. 3. Grid-connected PV system with proposed optimization technique.

The behavior of the projected technique is examined when the PV irradiation is changed, which is shown in Fig. 4. And, in addition, it also demonstrates the resultant ac power that produced by the modelled PV system for every strategy when varying the solar irradiation level. In this work, a fuzzy controller with a single input and single output was designed. The power from PV is specified as input which is given to FLC and the modulation index is used to control the boost converter which is used to attain the output. For the input PV power and output modulation index, three membership functions were defined. The maximum range of $\mathrm{PV}$ power for the modulation index is ( 0 to 1$)$ and all three fuzzy rules are applied to the controller. 

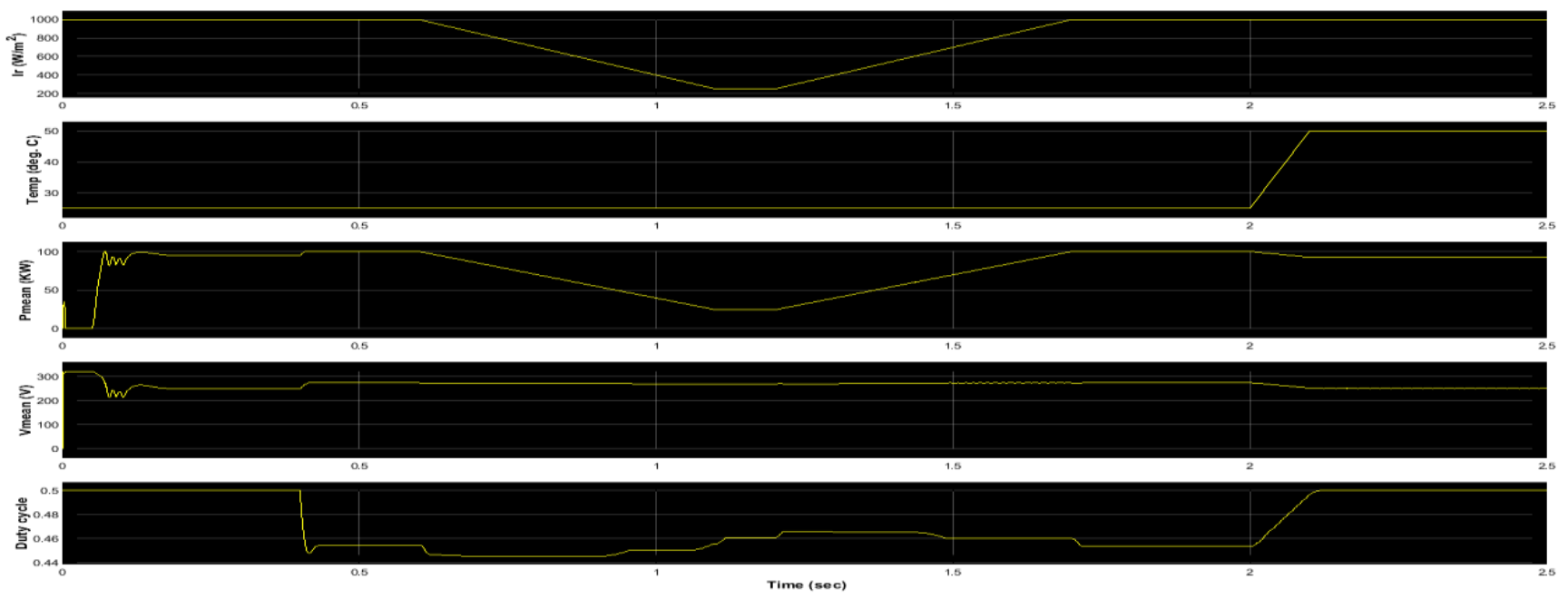

Fig. 4. The duty cycle and PV power at different irradiation and cell temperature.

The PV power, duty cycle of boost converter and grid parameters are analyzed at different conditions to check the improvement in power quality. The grid parameters like voltage and current is given in Fig. 5. In addition, PV power alone is shown in Fig 6.

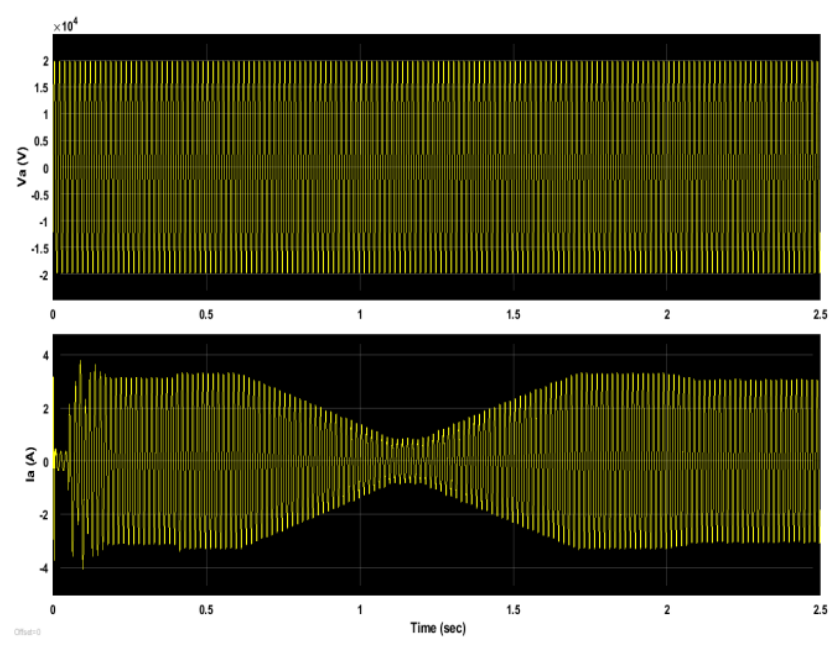

Fig. 5. Grid parameters of voltage and current.

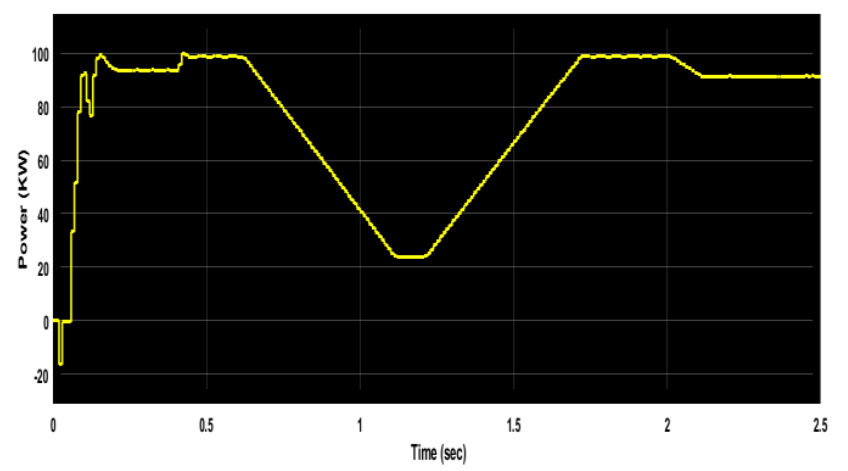

Fig. 5. Extracted PV Power.

The harmonic analysis of load side current is done at different conditions and its measurement is given in Fig 7. In the earlier studies, PQ of PV system output was improved using PI controller and ANN-PI controller. The PI controller reduced the THD only up to $11 \%$ in grid current and the results from ANN-PI also had $7 \%$ THD. The above results concluded that the PSO-FLC based optimization technique is very effective in dynamic weather conditions and gives lesser harmonics compared to other techniques.

Furthermore, FFT analysis of the inverter output current is given in Fig. 7, as seen from this figure THD level of this current is $3.64 \%$. The presentation of the suggested technique was assessed by means of the comparison analysis with the presented technique. The assessment properties represent that the projected technique could be a favorable solution for PQ improvement of the PV systems under grid side faults, which is proficient over the other conventional techniques which is mentioned in below section.

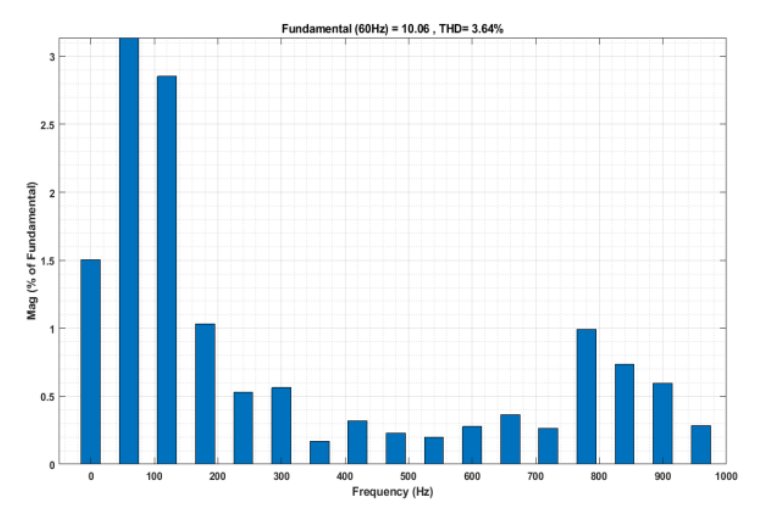

Fig. 7. THD measurement of 3-level MLI.

From the comparison derived from table II, it clearly shows that the THD of the proposed controller is much superior over the existing techniques [11] and [12]. It can determine that the projected technique effectively enhances the PQ of the grid-connected PV system compared to the conventional techniques.

From Figs. 7, 8, and 9, it illustrates the THD values for the 3, 5 level and 27-level MLI. From table II, it clearly explains the THD analysis for the various level of MLI with different techniques. 
Table II: Comparison of THD analysis.

\begin{tabular}{|l|l|}
\hline Solution Techniques [20], [21] & 3-level MLI \\
\hline Without Controller & 24.97 \\
\hline PI Controller & 12.86 \\
\hline ANN-PI Controller & 8.44 \\
\hline RBFNN Controller & 4.81 \\
\hline Improved IC-MPPT algorithm & 17.95 \\
\hline Proposed (ACSA-FLC) Controller & 3.64 \\
\hline
\end{tabular}

\begin{tabular}{|l|c|}
\hline Solution Techniques [20], [21] & 27-level MLI \\
\hline PSPWM controller & 17.14 \\
\hline PSPWM and Modified SOPWM & 6.59 \\
\hline ACSA Controller & 6.05 \\
\hline FLC Controller & 5.87 \\
\hline Hybrid ACSA-FLC controller & 5.62 \\
\hline
\end{tabular}

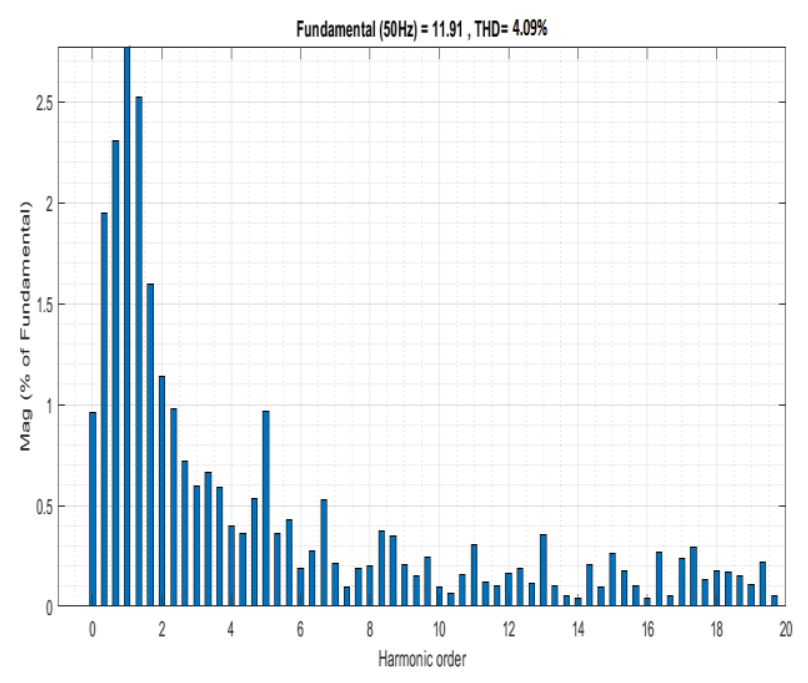

Fig. 8. THD measurement of 5-level MLI.

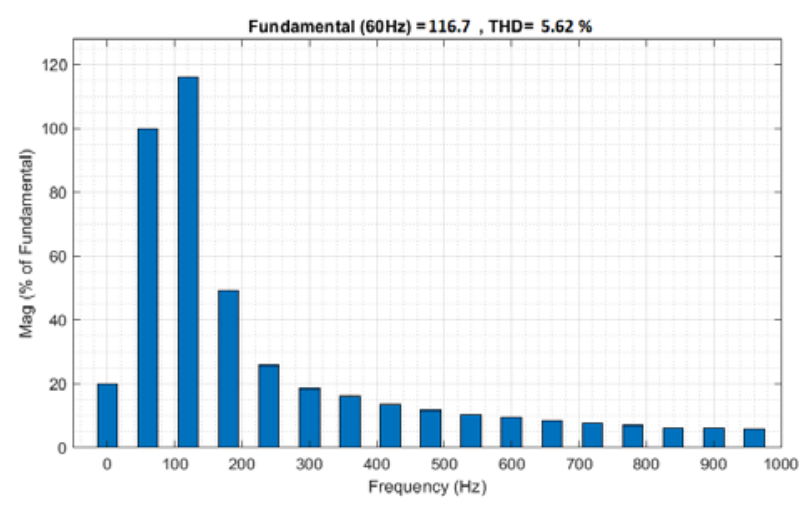

Fig. 9. THD measurement of 27-level MLI.

\section{Conclusion and future Work}

MLIs have been extensively employed to improve the PQ of the PV systems. However, the need for large number of components, higher standing voltage, and high harmonic content in the output of a conventional MLI greatly affects the system efficiency. Here, in this research, a hybrid control strategy (for example; hybrid neural network with whale optimization algorithm, hybrid shuffled frog leap Algorithm with ant lion optimizer, or glow-worm swarm optimization with rule based techniques) is considered, with suitable level of inverter (5 level, 15 level, or 27 level with less number of switches) to reduce the PQ issues present in the system. The hybrid control strategy will be applied to determine the optimum switching angles for the MLI which will reduce the complexity of the calculations.

\section{Acknowledgement}

This work has been partially supported by the Spanish Ministerio de Ciencia, Innovación y Universidades (MICINN)-Agencia Estatal de Investigación (AEI) and the European Regional Development Funds (FEDER), by project PGC2018-098946-B-I00.

\section{References}

[1] Zhou, Yan, and Hui Li. "Analysis and suppression of leakage current in cascaded-multilevel-inverter-based PV systems." IEEE Transactions on Power Electronics 29, no. 10 (2013): 5265-5277.

[2] Jain, Sachin, and Venu Sonti. "A highly efficient and reliable inverter configuration based cascaded multilevel inverter for PV systems." IEEE transactions on industrial electronics 64, no. 4 (2016): 2865-2875.

[3] Das, Soumya Ranjan, Prakash K. Ray, Alok K. Mishra, and Asit Mohanty. "Performance of PV integrated multilevel inverter for PQ enhancement." International Journal of Electronics (2020): 1-38.

[4] Chattopadhyay, Sumit K., and Chandan Chakraborty. "A new asymmetric multilevel inverter topology suitable for solar PV applications with varying irradiance." IEEE Transactions on Sustainable Energy 8, no. 4 (2017): 1496-1506.

[5] Rajalakshmi, Sambasivam, and Parthasarathy Rangarajan. "Investigation of modified multilevel inverter topology for PV system." Microprocessors and Microsystems 71 (2019): 102870.

[6] Pourfaraj, Alireza, Mohammad Monfared, and Hamed Heydari-doostabad. "Single-phase dual-mode interleaved multilevel inverter for PV applications." IEEE Transactions on Industrial Electronics 67, no. 4 (2019): 2905-2915.

[7] A. I. Ali, Mahmoud A. Sayed, and Essam EM Mohamed. "Modified efficient perturb and observe maximum power point tracking technique for grid-tied PV system." International Journal of Electrical Power \& Energy Systems vol. 99, pp. 192-202, 2018.

[8] H. A. Mosalam, Ragab A. Amer, and G. A. Morsy. "Fuzzy logic control for a grid-connected PV array through Zsource-inverter using maximum constant boost control method." Ain Shams Engineering Journal vol. 9, no. 4, pp. 2931-2941, 2018.

[9] M. Lakshmi, and S. Hemamalini. "Decoupled control of grid connected photovoltaic system using fractional order controller." Ain Shams Engineering Journal vol. 9, no. 4, pp. 927-937, 2018.

[10] M. Aourir, A. Abouloifa, I. Lachkar, C. Aouadi, F. Giri, and J. M. Guerrero, "Nonlinear control and stability analysis of single stage grid-connected photovoltaic systems". International Journal of Electrical Power \& Energy Systems, vol. 115, pp. 105439, 2020.

[11] B.G. Sujatha, and G. S. Anitha, "Enhancement of PQ in grid connected PV system using hybrid technique," Ain Shams Engineering Journal, vol. 9(4), pp. 869-81, December 2018.

[12] N. Prabaharan, A. Rini Ann Jerin, K. Palanisamy, and S. Umashankar, "Integration of single phase reduced switch multilevel inverter topology for grid connected photovoltaic system," Energy Procedia, vol. 138, pp. 1177-1183, October 2017. 